\section{INTRACRANIAL AND INTRAVASCULAR PRESSURES} University of Minnesota, Department of Pediatrics, and Children's Hospital, St. Paul, MN

Do airway pressures effect intracranial and intravascular pressures? If so, does one component of the respiratory cycle have more of an effect than another? The cerebral and vascular effects of changes in I:E ratio, peak inspiratory pressure, and PEEP were examined in 11 paralyzed, anesthetized cats. While oxygen saturation, end tidal $\mathrm{CO}_{2}$, and mean airway pressures wer held constant, I:E ratios, peak ${ }^{2}$ inspiratory pressures, and PEEP were individually varied. Intracranial pressure (ICP), central venous pressure (CVP), and aortic pressures were continuously recorded and cerebral tissue perfusion pressures were calculated. Two animals developed fatal cerebral hemorrhages when I:E ratios were reversed $(2: 1)$. In the 9 surviving animals, ICP, CVP, aortic pressure, and cerebral tissue perfusion pressures varied directly with mean airway pressures. As mean airway pressures increased, ICP and CVP increased; aortic pressure and cerebral tissue perfusion pressures decreased. Equivalent changes in I:E ratio and peak inspiratory pressures appeared to have a greater effect on the vascular pressures than did changes in PEEP. (Supported by a grant from the Hennepin County Lung Association, Minneapolis, MN.)
Stephen J. Boros, Michael Coleman, Margaret J.Gordon

1633 OBSTRUCTIVE SLEEP APNEA IN INFANTS AND CHILDREN. Robert T. Brouillette and Carl E. Hunt. Northwestern University and Children's Memorial Hospital, Department of Pediatrics, Chicago, Illinois.

Twenty-one infants and children with obstructive apnea during sleep have been evaluated. Prolonged delays in referral resulted in cor pulmonale in 11 patients, failure to thrive in three and permanent hypoxic brain damage in one. In all cases, a history suggesting sleep-related partial or complete airway obstruction during sleep (snoring, retractions, absent breathing sounds with continued breathing effort) was obtained. Whereas the physical exam of the awake patient was typically normal, examination during sleep was usually diagnostic. Polygraphic monitoring (EKG, heart rate, $\mathrm{tcPO}_{2}$, end-tidal $\mathrm{CO}_{2}$, chest and abdominal strain gauges) vias helpful in documenting the degree of abnormality. Twelve patients were improved by tonsillectomy and/or adenoidectomy. Nine others required tracheostomy to bypass the upper airway obstruction. Anatomic airway abnormalities were present in at least two-thirds of the latter cases: micrognathia (3), cleft palate repair (1), generalized facial abnormalities associated with Larsen's syndrome and Crouzon's disease (2). All patients were improved after surgical treatment; however, hypoventilation during sleep remained in five. Obstructive apnea occurred predominantly during sleep, when airway maintaining muscles are hypotonic, and usualiy in patients with anatomic upper airway abnormalities. These associations support the concept that the pharyngeal airway collapses when negative inspiratory pressure exceeds the force of airway

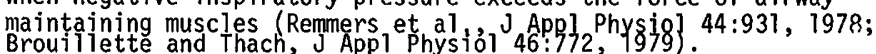

1634 CHANGING PATTERN OF CHEST WALL MOVEMENTS IN RESPIRAPULMONARY CHANGES IN NEONATAL GUNN RATS EXPOSED TO $\mathrm{O}_{2}$ AND PHOTOTHERAPY. Frank Bowen, Jr., Rachel Porat,

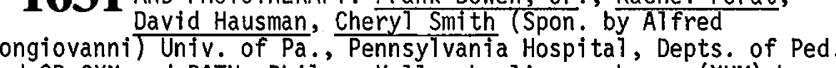
and OB-GYN and PATH, Phila. Yellow hyaline membrane (YHM) have been correlated with hyperbilirubinemia (HBILI) and with bronchopulmonary dysplasia. Also data have suggested a protective effect of HBILI on 02 damage to lungs and a role of phototherapy $(P)$ in the development of lung damage. To test the relationship of $\mathrm{P}$, HBILI and high $\mathrm{F}_{\mathrm{I}} \mathrm{O}_{2}$, and to develop a model for study 7 to 13 day old GUNN rats ( $j j$ and $J j$ phenotypes) were exposed to four experimental conditions for 24 to 72 hours: I) $\mathrm{FIO}_{\mathrm{O}}>.75+\mathrm{P}$, II) $\mathrm{F}_{\mathrm{I}} 02>.75$ wi thout $\mathrm{P}$, III) $\mathrm{FI}_{\mathrm{I}} 02.21+\mathrm{P}$ and IV) $\mathrm{F}_{\mathrm{IO}} \mathrm{O}_{2} .21$ wi thout $\mathrm{P}$. Hct. Indirect $\mathrm{Bi} 1 \mathrm{i}$ were measured. The lungs were examined in a masked fashion. Results:
III

15
32.9
1.0

11.00

11.15
1.0
9.52

$6 / 7$

\section{IV}

6

31.3

9.58

9.0
8.97
0.3

$0 / 3$

$\begin{array}{lcll}1.0 & 1.0 & 1.0 & 1.0 \\ 8.73 & 11.88 & 9.52 & 8.97 \\ 3 / 8 & 5 / 11 & 2 / 7 & 0 / 3 \\ 1 / 11 & 2 / 9 & 6 / 9 & 0 / 3\end{array}$

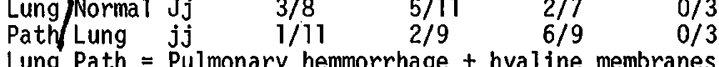

The Data indicate no effect of 02 and $P$ in acute phase lung damage but suggest $a$,protective effect of HBILI. Additional study with longer exposure and larger numbers are needed.

1632

HYPEROXIA DAMAGES ENDOTHELIAL CELLS IN TISSUE CULTURE C. Michael Bowman, Ruth N. Harada, Sara DeLong, Albert E. vatter and John E. Repine (Spon. by Ernest K. Cotton) University of Colorado Health Sciences Center, WebbWaring Lung Institute, Denver.

When exposed to hyperoxia, patients and animals develop significant lung injury which may lead to respiratory failure and even death. Changes seen in lungs exposed to hyperoxia indicate that endothelial cell damage with vascular leak is a prominent and early feature of the pathophysiology of pulmonary oxygen toxicity. We hypothesized that hyperoxia directly damages endothelial cells, leading to vascular leak and compromise of gas exchange. To test this hypothesis, we exposed monolayers of bovine pulmonary artery endothelial cells to hyperoxia $\left(95 \% 02-5 \% \mathrm{CO}_{2}\right)$ or normoxia $\left(80 \% \mathrm{~N}_{2}-15 \% \mathrm{O}_{2}-5 \% \mathrm{CO}_{2}\right)$ at ambient atmospheric pressure for $24,48,72$ and 96 hours. We found that exposure to hyperoxia caused increasingly severe morphologic changes in endothelial cells, manifested by clumping of nuclear material and gross cytoplasmic disorganization. Such changes appeared in increasing proportions of cells between 24 and 96 hours of hyperoxic exposure, but were rarely seen in cells exposed to normoxia. These changes are quite similar to those found in the lung endothelial cells of animals exposed to hyperoxia. We also found increasing release of cytoplasmic lactic dehydrogenase from the hyperoxia-exposed but not normoxia-exposed cells. These results suggest that hyperoxia alone can damage pulmonary endothelial cells and support the possibility that this mechanism may contribute to the respiratory failure seen in oxygen toxicity.
F.G.A.Versteegh, M.Pultusker, S.Robertson, A. Fanaroff

Dept. of Ped., Case Western Reserve University, Cleveland, Ohio

To determine the influence of RDS on chest wall (CW) movements

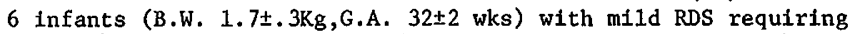
$\mathrm{O}_{2}$ for $\geq 3$ days and 8 infants (B.W. $1.7 \pm .5 \mathrm{Kg}$, G.A. $33 \pm 2$ wks) without cardiopulmonary disease were studied for $60 \mathrm{~min}$ on days 1,3 and 7. We determined $\mathrm{CW}$ movements by strain gauges over upper (URC), lower (LRC) ribcage and abdomen, airflow by nasal thermistor, transcutaneous (Tc) $\mathrm{PO}_{2}$ and $\mathrm{PCO}_{2}$ and behavioral state through out each study. Asynchronous (Asyn) CW movement was defined as inward ribcage motion during inspiration. Total duration of apneic episodes $\geq 5 \mathrm{sec}$ was calculated/hour. Asyn URC movements and apneic time increased abruptly by day 7 in infants with BDS and gradually in the non-RDS group. LRC was largely Asyn in both gps.

\begin{tabular}{|c|c|c|c|c|}
\hline & $\%$ Asynchronous & URC Movements & Apneic & $1 \mathrm{me}(\mathrm{min})$ \\
\hline & RDS & Non-RDS & RDS & Non-RDS \\
\hline Day 1 & $2 \pm 2$ & $11 \pm 13$ & $.1 \pm .1$ & $1.1 \pm 2.4$ \\
\hline Day 3 & $7 \pm 9$ & $26 \pm 23$ & $.4 \pm .4$ & $2.1 \pm 2.6$ \\
\hline Day 7 & $39 \pm 11$ & $46 \pm 23$ & $2.1 \pm 2.2$ & $1.7 \pm 1.6$ \\
\hline Day 1 vs 7 & $p<.005$ & $\mathrm{p}<.05$ & $\mathrm{p}<.05$ & NS \\
\hline Day 3 vs 7 & $p<.01$ & NS & $p<.05$ & NS \\
\hline
\end{tabular}

Day 3 va 7 or over time. These data suggest that RDS enhances respiratory drive and intercostal muscle activity with a resultant decrease in Asyn URC movements and apnea. The comparable blood gases of the two groups suggest that nonchemical factors are responsible for the increased respiratory drive in infants with RDS.

EFFECTS OF INTENSIVE IN-HOSPITAL THE

1635 FUNCTIONS AND EXERCISE TOLERANCE IN CYSTIC FIBROSIS (CF). Frank J. Cerny, Gerd J. Cropp. State Univ. of N.Y., Children's Hospital, Dept. of Pedlatrics, Buffalo, N.Y. There is little information on the objective benefits of inhospital therapy in CF. We, therefore, studied the effects of a 13 day \pm 2.6 SD (range 10-18 days) admission on lung functions and exercise capacity in $15 \mathrm{CF}$ patients with moderate to severe disease. Treatment consisted of intravenous antibiotics, postural dratnage and exercise therapy. We measured resting vital capacity (VC), residual volume (RV), total lung capacity (TLC), forced expired volume in 1 second $\left(F E V_{1}\right)$, specific atrway conductance (SG), arterial oxygen saturation ( $\mathrm{SaO}_{2}$ ), and exercise adaptation and tolerance shortly after admission and before discharge. Adaptation to exercise was evaluated by the work capacity (Watts $/ \mathrm{kg}$ ), peak heart rate (PHR), exercise-Induced changes in $\mathrm{SaO}_{2}$ and the ratio of PHR to peak $W / \mathrm{kg}$.

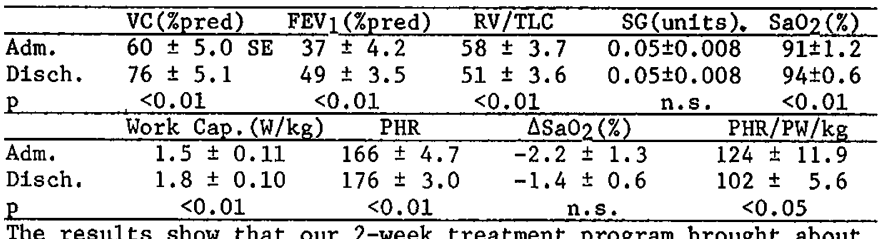

(hilew that our 2-week treatment program brought about ebjective improvements in lung function, exerclse tolerance and exercise adaptation in $\mathrm{CF}$ patients. 